CherniaK, R.M. \& CherniAK, L. (1961) Respiration in Health and Disease, p. 30. Saunders, Philadelphia.

Cranston, W.I., PePper, M.C. \& Ross, D.N. (1955) Carbon dioxide and control of respiration during hypothermia. J. Physiol. (Lond.), 127, 380.

Dammann, J.F., Thung, N. \& Littlefield, J.B. (1963) The management of the severely ill patient after open-heart surgery. J. thorac. cardiovasc. Surg. 45, 80.

Galletti, P.M. \& Brecher, G.A. (1962) Heart Lung Bypass, p. 222. New York.

Gerbode, F., Osborn, J.J. \& Johnstone, J.B. (1960) Experience with perfusion hypothermia using an improved rotating disc oxygenator. Thorax, $15,185$.

HoBsley, M. (1963) Respiratory disturbances caused by general surgical operations. Ann. roy. Coll. Surg. Engl. 33, 105.

Johnstone, J.H., Lawson, L.J. \& Mucklow, R.G. (1965) Metabolic changes after aorto-iliac occlusion. Brit. med.J. ii, 974.

LAwson, L.J. (1965) Parenteral nutrition in surgery. Brit. J. Surg. 52, 795.

Litwin, M.S. (1958) Extracorporeal Circulation, p. 350. Allen.

NunN, J.F. \& PAYNe, J.P. (1962) Hypoxaemia after general anaesthesia. Lancet, ii, 631.

RAISON, J.C. (1965) Acid base changes and tissue respiration in extracorporeal circulation. Ann. roy. Coll. Surg. Engl. 37, 93.

\title{
Discussion to the paper by L. J. Lawson
}

Brooks. Studies such as those carried out by Dr Lawson are long overdue in this country. There are, however, aspects upon which I would like to comment.

In the field of acid-base balance a number of anomalies may be present. For example, porta-caval anastomosis may produce a number of metabolic disorders which include hyponatraemia, hyper- or hypo-kalaemia, intolerance to a high oral protein intake which precipitates hepatic coma even in the absence of pre-operative hepatic dysfunction, and metabolic acidosis (Hubbard, 1958). The fall in bicarbonate ion concentration in most cases of porta-caval anastomosis is of much greater significance because patients with cirrhosis of the liver usually have a raised plasma bicarbonate concentration. They also have low $\mathrm{PCO}_{2}$ because of increased alveolar ventilation, and the blood pH is therefore high (Brooks, 1967). When liver damage is very severe, e.g. if liver necrosis develops, a marked metabolic acidosis is observed which does not respond to infusion of sodium bicarbonate.

The metabolic changes that occurred during replacement of the abdominal aorta as shown on Dr Lawson's slide, are very similar to those found in that type of case by myself. It is quite true that if the aorta is clamped for only half an hour during an elective procedure, for example for claudication where anastomotic vessels have already developed only a moderate degree of metabolic acidosis is found together with a small rise in blood lactate and blood pyruvate.

If, however, the aorta is replaced during an emergency operation for a leaking abdominal aneurysm and the aorta is clamped for long periods, e.g. $3 \mathrm{hr}$ or more, then a marked metabolic acidosis develops and this is associated with hypotension that does not respond to blood transfusion (Brooks \& Feldman, 1962; Knight, 1963). Correction of the metabolic acidosis by infusion of sodium bicarbonate solution results in a dramatic rise in blood pressure in a similar manner to that reported yesterday (McConn, Fig. A8, p. 224).

Post-operatively a metabolic alkalosis frequently develops and this is thought by Moore (1959) to be due to the citrate infused with stored blood. However, an increase in the plasma bicarbonate ion concentration can also be observed following blood transfusion. It is also of interest to note that following major vascular and cardiac surgery the blood lactate and pyruvate may be raised even in the presence of a metabolic alkalosis.

Acute renal failure is a relatively rare condition but post-operative oliguria is commonly seen. Oliguria very rarely develops into acute renal failure and I am not convinced that mannitol is at all effective in preventing the onset of acute renal failure. Sometimes mannitol will produce a diuresis for very brief periods before acute renal failure is fully developed and is then later completely ineffective. The mechanism of this is too involved to discuss at this moment but it is possible that in these circumstances mannitol is filtered through glomeruli that lie near the surface of the kidney from which loops of Henle arise which are confined to the cortex, never entering the medulla and therefore the concentrating areas.

It is correct to stress the importance of parenteral nutrition in some cases. We too have been able to obtain a positive nitrogen balance in post-operative patients by this means, using a synthetic amino acid preparation containing sorbitol.

\section{References}

Brooks, D.K. (1967) Resuscitation, p. 57. Edward Arnold, London.

Brooks, D.K. \& Feldman, S.A. (1962) Metabolic acidosisA new approach to neostigmine-resistant curarisation. Anaesthesia, 17, 161 .

HubBaRD, T.B. (1958) Carcinoma of the head of the pancreas: resection of the portal vein and portacaval shunt. Ann. Surg. 147, 935.

KNIGHT, P.F. (1963) Anaesthesia for the leaking abdominal aneursym. Anaesthesia, 18, 151.

MOORE, F.D. (1959) Metabolic Care of the Surgical Patient, p. 858. Saunders, Philadelphia. 